\title{
2000-2018 Yılları Arasında Çad Ekonomisinin Makro Ekonomik Görünümü
}

\author{
Abdallatif Mahamat Yacoub \\ Doktora Öğrencisi, Necmettin Erbakan Üniversitesi, Sosyal Bilimler Enstitüsü, İktisat, Konya, Türkiye. \\ Ben.yacoub.amy@gmail.com
}

\begin{tabular}{|c|c|}
\hline Makale Bilgileri & ÖZ \\
\hline $\begin{array}{l}\text { Anahtar Kelimeler: } \\
\text { Makro ekonomik } \\
\text { göstergeler, Çad } \\
\text { Ekonomisi, Milli gelir, } \\
\text { İşsizlik, Cari işlemler } \\
\text { dengesi, Yabanci } \\
\text { Sermaye, Finans } \\
\text { sektörü. }\end{array}$ & $\begin{array}{l}\text { Bu çalışmada, 2000-2018 yılları arasında Çad ekonomisinin makro ekonomik göstergeleri } \\
\text { incelenmiştir. Çad } 2003 \text { yılından itibaren petrol üretici bir ülke haline gelmiştir. Bu önemli petrol } \\
\text { projesi Çad ekonomisine yeni dinamikler sağlamıştır. Çalışmadan elde edilen bulgular neticesinde, } \\
\text { Çad ekonomisinin son dönemdeki makro ekonomik olarak istikrarı henüz yakalayamadığını } \\
\text { söylenebilir. Bu durumun nedenleri arasında, uluslararası ticarete konu olan sektörlerin sınırlığı ve } \\
\text { buna bağlı olarak yatırım çekme kabiliyetindeki eksiklikler gösterilebilir. Ekonomideki kırılganlığın } \\
\text { bir yandan petrol ihracatına yoğun bağımlılık nedeniyle fiyat dalgalanmalarına, diğer yandan ise } \\
\text { ekonomik faaliyetlerin pamuk, canlı hayvan ve Arap zamkı gibi az sayıdaki sektörde } \\
\text { yoğunlaşmasından kaynaklandığı söylenebilir. Ekonomik anlamda çeşitlendirme politikalarının } \\
\text { uygulanması ve dış şoklara daha az maruz kalan sektörlere de yatırım yapılması ile bu durumun } \\
\text { olumsuz etkileri azaltılabilir. Ayrıca, yapısal bir görünüm arz eden işsizlik ve özellikle genç işsizlik } \\
\text { sorununun aktif işgücü politikaları ekseninde yeniden gözden geçirilmesinin gerekli olduğu } \\
\text { görülmektedir. Son olarak, ekonomik istikrara paralel şekilde siyasal istikrarın sağlanması da } \\
\text { ekonomi politikalarını etkinliğini artırabilecektir. }\end{array}$ \\
\hline
\end{tabular}

JEL Kodları: E20,

E30, G20

\section{Macro-Economic Outlook of Chad Economy Between 2000-2018}

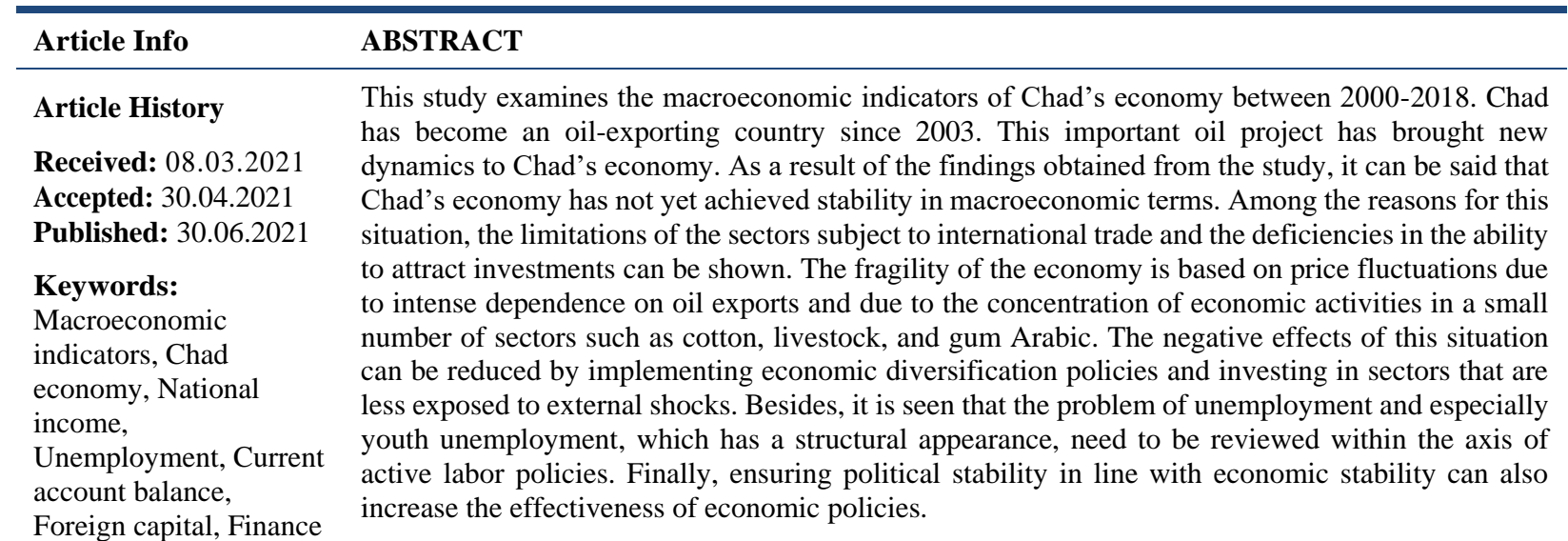
sector.

JEL Codes: E20, E30, G20

Atıf/Citation: Yacoub, A. M. (2021). 2000-2018 Yılları Arasında Çad Ekonomisinin Makro Ekonomik Görünümü, Necmettin Erbakan Üniversitesi Siyasal Bilgiler Fakültesi Dergisi, 3(1), 52-67. 


\section{GíRiș}

İktisadi bakımdan bir ekonominin istikrarının göstergesi olarak büyüme hızı, işsizlik, enflasyon, dış ticaret açığı gibi birçok değişkenin kullanabilmesi mümkündür. Ekonominin istikrarı ülke içindeki iktisadi aktörler açısından önemli olduğu kadar, uluslararası aktörler ve kurumlar açısından da büyük bir öneme sahiptir. Politika yapıcıları, politikaları tasarlamak ve değerlendirmek için istatistiksel göstergeler belirleyicidir. Ülke yerleşikleri ve yabancı yatırımcılar, siyasi yönetim anlayışını ve performansını değerlendirmek için bu göstergeleri ölçüt olarak kullanırlar (Mügge, 2016: 410).

Çad, her şeyden önce bir tarım ülkesidir. Nitekim tarım, Çad ekonomisinin en önemli bileşenidir. Bu sektör işgücünün \% 75 'inden fazlasını istihdam etmekte ve yaklaşık 39 milyon hektarlık bir ekilebilir arazi alanına sahiptir (ancak bu alanın sadece 2,2 milyon hektar kullanımdadır). Hayvancılığın hacmi ve kalitesi, Çad'a birçok potansiyel sunmaktadır. Bu arada, ekonomik yapıyı ciddi biçimde etkileyen bir gelişme olarak Çad'da 2003 yılından beri petrol üretilmektedir. Petrol projesi, Çad ekonomisine yeni dinamikler sağlayıp son yıllarda petrol alanındaki yoğun ihracat çalışmaları ile ülkenin gayri safi yurtiçi hasılasının (GSYH) yıllık büyüme hızını arttırmıştır. 2004 yılında büyüme rekor seviyeye ulaşarak \%33,63 olarak gerçekleşmiştir. Ancak son yıllarda petrol fiyatlarındaki düşüş olgusuyla birlikte 2015'te Çad'ın GSYH'si ancak \%1,8 büyümüş, 2016 yılında ise \%7'lik küçülme ile 2000 yılından bu yana en düşük büyüme oranı gerçekleşmiştir.

2000'li yıllar sonrasında istatistiksel verilerin önemi oldukça artmıştır. Bu veriler ülkelerin sadece ekonomi politikası değil, aynı zamanda sağlık, eğitim, çevre, ulaştırma, tarım ve hayvancılık politikalarının da belirlenmesinde yönlendirici olmaktadır. Politika yapıcılarının rasyonel karar almaları ve reel strateji uygulayabilmeleri için makroekonomik göstergeleri belirleyen sebepleri dikkate almaları gerekmektedir. Bu çalışmada Çad ekonomisinin 2000-2018 yılları arasında istatistiksel veriler ile makroekonomik göstergelerin hangi yönde etkileşim gösterdiği teorik olarak incelenecektir. Ekonomik göstergelerde meydana gelen değişikliklerin izlediği seyir uygulanacak politikalara 1şık tutacağ öngörülmektedir.

Bu çalışmada Çad ekonomisinin 2000-2018 yılları arasında makro ekonomik görünümü incelenerek ekonomik performansı üzerinde bir değerlendirme yapılmaktadır. Bu çerçevede ilk olarak Çad ekonomisinin milli gelir göstergeleri konusu ele alınmaktadır. Sonrasında Çad' da işgücüne katılım ve enflasyona ilişkin göstergeler incelenmektedir. Daha sonra cari işlemler dengesi, yabancı sermaye ve finansal sektöre ilişkin genel görünüm üzerinde durulmaktadır. Son olarak, çalışmadan elde edilen bulguların genel değerlendirmesine sonuç kısmında yer verilmektedir.

\section{1.ÇAD EKONOMISINIIN MILLİ GELİR GÖSTERGELERİ}

Milli gelir hesaplaması ve analizi makro ekonominin ilgilendiği en önemli konulardan birisidir. Milli gelir göstergeleri ekonomiyi bir bütün olarak ele almakta, bu göstergelerdeki değişim ekonominin performansı ile ilgili önemli fikirler vermektedir. $\mathrm{Bu}$ çerçevede günümüzde ülkeler arası karşılaştırmalarda en çok kullanılan milli gelir göstergelerinin GSYH, büyüme oranı ve kişi başına düşen GSYH göstergeleri olduğu söylenebilir.

Çad ekonomisinin tarihsel gelişimi incelendiğinde, bağımsızlıktan, yani 1960 yılından 1990 yılına kadarki dönemde ekonomik performansın pek de parlak olmadığı görülmektedir. Bağımsızlıktan sonra siyasi istikrarsılılı̆ın başlaması ve iç savaşların ortaya çıkmasıyla birlikte ekonomik büyüme rakamları düşük seviyelerde kalmıştır. 1990-2000 yılları arasında Çad, devletini yeniden inşa edip, yeni yapısal uyum politikaları uygulamıştır. Bu dönemdeki yapısal uyum politikaları, özelleştirme hareketleri ve 
uluslararası ticaretin serbestleştirmesi ile Çad'ın ekonomik performansında iyileşme görülmüş, yıllık büyüme rakamları ve kişi başına gelir artmaya başlamıştır.

Çad, 2003 yılından itibaren petrol üreticisi bir ülke haline gelmiştir. Bu önemli petrol projesi Çad ekonomisine yeni dinamikler sağlamıştır. Proje ile Çad GSYH'si artmıştır. Şekil 1'de gösterildiği gibi, 2000 yılında GSYH 1,57 milyar Amerikan doları idi. Ancak 2003 yılında gerçekleştiren ilk petrol ihracatı ile GSYH 2,25 milyar dolara yükselip, 2014 yılında 13,98 milyar dolara ulaşmıştı. Son y1llarda petrol fiyatlarındaki düşüş ile birlikte ise Çad'ın gelir göstergeleri düşmeye başlamıştır. GSYH 2015'te 10,94 milyar dolara, 2017’de 9,87 milyar dolara kadar düşmüştür.

2003 yılından beri petrol sektöründeki yoğun ihracat çalışmaları ile Çad'ın GSYH yıllık büyüme oranları yükselmeye başlamış, aşağıdaki şekil 2'de gösterildiği gibi 2004'te rekor seviyeye ulaşmış ve \%33,6 oranında büyümüştür.

Ancak petrol ihracatının yıllık ortalaması 57 milyon varil olan, 2006-2008 yılları arasında Çad petrolü içinde suyun varlığının keşfedilmesiyle ve ayrıca 13 Nisan 2006'da başarısız askeri darbe girişimi ile ihracatın yıllık ortalamasında \%9'luk bir düşüş yaşanmıştır (Banque Africaine de Développement, 2009: 3). Bunun neticesinde GSYH y1llık büyüme oranı 2006 y1lında \%0,65 seviyesinde gerçekleşmiştir. Bunun yanında uluslararası düzeyde petrol fiyatlarındaki düşüş, Çad'ın ekonomisi üzerinde olumsuz etkiler yaratmıştır. 2014'te Çad'da petrol ihracatından elde edilen gelir, Çad'ın tüm ihracat gelirinin \%90'ını, bütçesinin \%60'ını ve GSYH'nin \%30'unu oluşturmaktaydı. 2015 yılında petrol ihracatından elde edilen gelirlerdeki düşüşler nedeniyle Çad'ın bütçe açığının 400 milyar FCFA olduğu tahmin edilmiştir (Nations Unies- Undaf, 2017: 11).

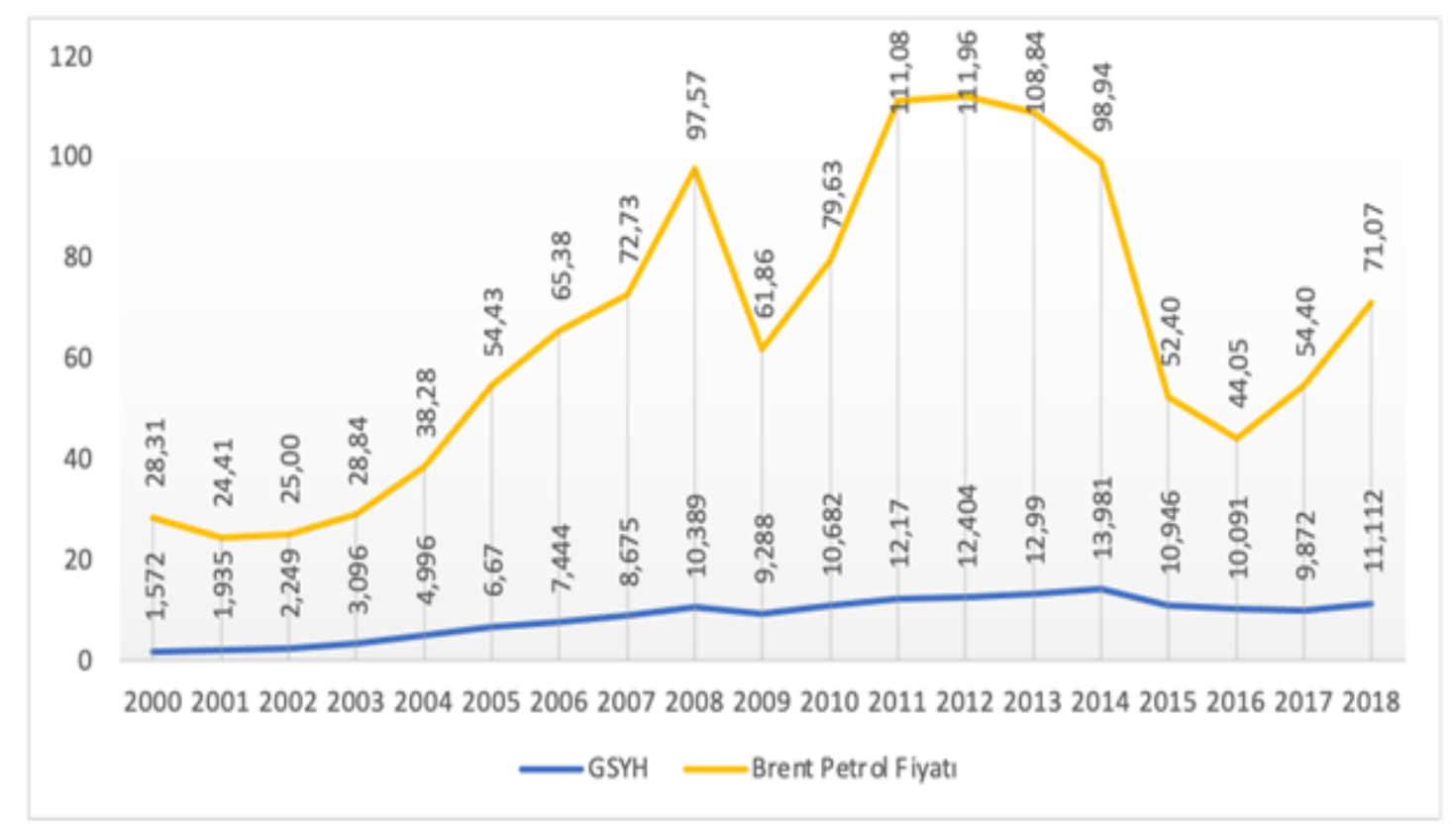

Şekil 1. Çad'ın GSYH'sının Seyri, (2000-2018, cari fiyatlar, Milyar ABD Doları) ve Petrol Fiyatlarındaki Ylllık Değişimi

Kaynak: IMF Data Base ve Federal Reserve Economic Data (2021).

$\mathrm{Bu}$ gelişmeler doğrultusunda, son yıllarda petrol fiyatlarında ortaya çıkan düşüşle birlikte 2015 y1lında Çad'da GSYH büyüme oranı \%1,8'e gerilemiş, 2017 y1lında ise GSYH \%-6,4 oranında küçülerek 2000 y1lından bu yana gerçekleşen en büyük düşüş görülmüştür. 


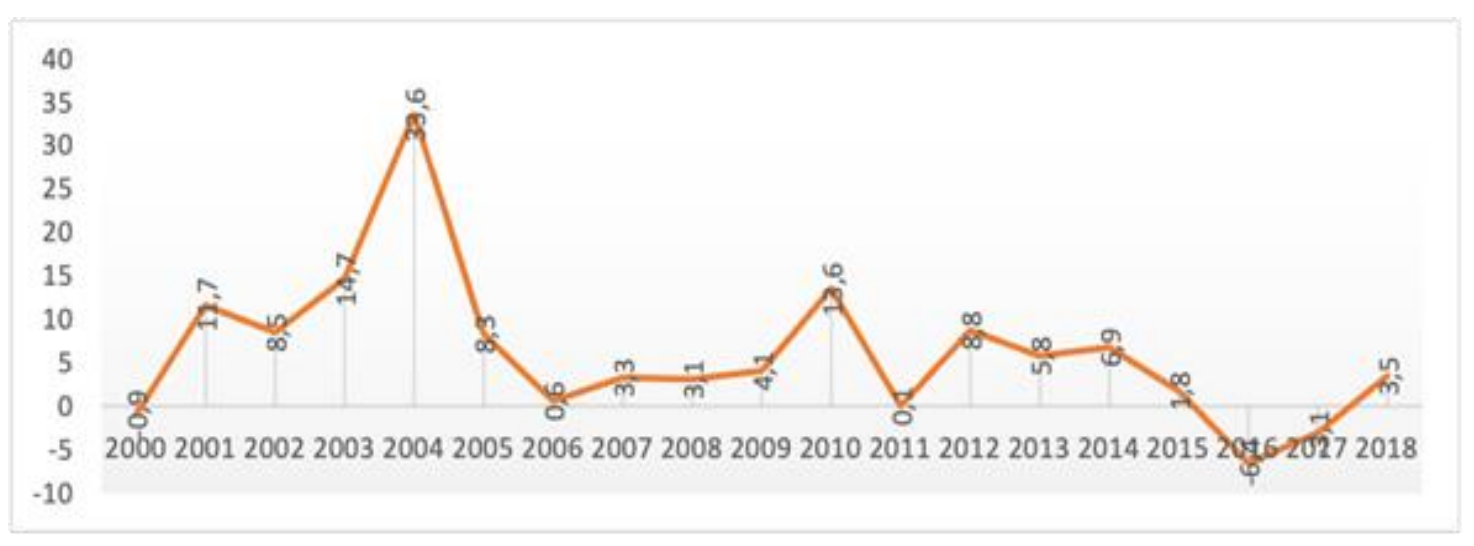

Şekil 2. 2000-2018 Döneminde Reel GSYH Ylllık Büyüme Oranları (\%)

Kaynak: IMF Data Base (2020).

Çad petrol ihracatına başlamadan önce, tarım sektörü GSYH'nin yaklaşı \%36'si ve ihracatın hemen hemen (özellikle pamuk, canlı sığır ve Arap zamkı) bütününü oluşturmakta idi. Günümüzde petrol sektörünün gelişimiyle tarım sektörü GSYH'nin sadece \%19'unu temsil etmektedir (Banque Africaine de Développement, 2009: 2).

Ülke ekonomilerinin gelişmişlik seviyeleri ile ilgili en önemli göstergelerden birisi olan kişi başına düşen GSYH rakamları açısından bakıldığında Çad, az gelişmiş ülkeler arasında yer almaktadır. Petrol ihracatının başlaması Çad'da kişi başına düşen GSYH'nin yükselmesine neden olmuştur. Şekil 3’te gösterildiği gibi 2000 yılında kişi başına düşen GSYH 210 dolar idi. Ancak 2003 yılında gerçekleştirilen ilk petrol ihracatı ile kişi başına düşen GSYH 360 dolar düzeyine, 2014 yılında ise 1239 dolara kadar yükselmiştir. Ancak son yıllarda petrol fiyatlarındaki düşüş ve Çad' daki ekonomik daralma ile birlikte Çad'ın kişi başına düşen GSYH rakamları da düşmeye başlamış, 2016 yılında 851 dolara ve 2017 yılında ise 810 Dolara kadar gerilemiştir.

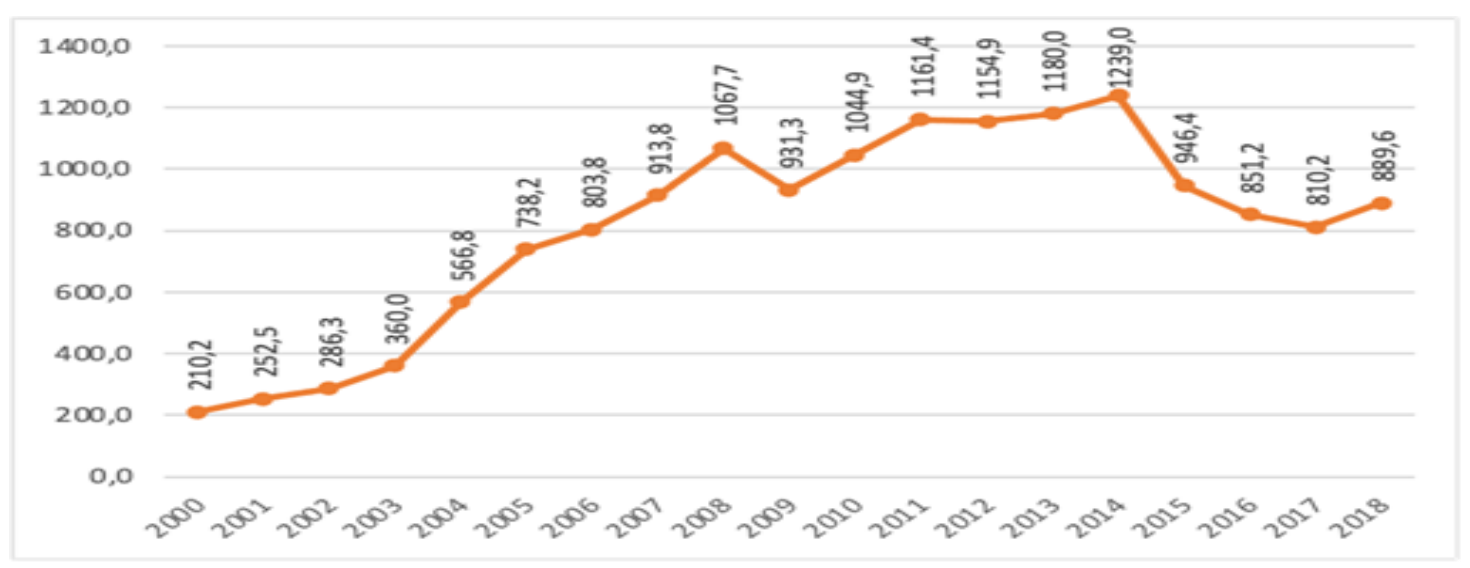

Şekil 3. 2000-2017 Döneminde Çad'da Kişi Başına Düşen GSYH (Cari fiyatlar, ABD Doları)

Kaynak: IMF Data Base (2020).

\section{2. ÇAD'DA İŞGÜCÜNE KATILIM ORANI}

Genel olarak işsizlik, eksik istihdam durumu ile ortaya çıkmaktadır. Bir bireyin işsiz olarak değerlendirilebilmesi için bazı şartları taşıması gerekmektedir. Uluslararası Çalışma Örgütü bu şartları; bireyin çalışma çağında olup referans dönemi içinde işinin olmaması, belirli bir süre içinde iş araması 
ve iş bulduğunda işe başlayabilecek durumda olması şeklinde tanımlamıştır. Buna göre işsiz, piyasadaki uygulanan cari ücret seviyesinde çalışmayı isteyen ve dolaysıyla iş aradığ 1 halde çalışma imkânı bulamayan kişilere denmektedir. Ekonomide bu duruma düşenlerin genel durumlarına işsizlik adı verilmektedir (Mizırak ve Karabulut, 2018: 174).

Çad'da çalışma yaşındaki nüfusun 6 milyon kişi olduğu tahmin edilmektedir. Bunların 1.276.000'i istihdam edilmektedir. İstihdamda birincil sektörler olan (tarım, balıkçılık ve hayvancılık) faaliyetlerinde çalışanlar geçmişte iş gücünün \%95'ini temsil ederken, 2016 y1lına geldiğinde şehir merkezine yapılan kırsal göç nedeniyle bu oran \%72'ye gerilemiştir. İkincil sektörler görece yoğun olmayan ve çeşitlendirilmemiş tarım şirketleri (bira, sigara, şeker) ve pamuk işleme tesislerinden (pamuk lifi, yağ değirmeni, sabun) oluşmaktadır. Üçüncül sektörler ise iş gücünün yaklaşık dörtte birini temsil eden ticaret, lojistik ve el sanatları olmakla birlikte, bu sektörler tarafından yaratılan katma değerdir. (CNUCED, 2016: 2).

Genel olarak işsizliğe bakıldığında, Çad'da gençlerin eğitim seviyelerine bakılmaksızın bir istihdam sorunu ile karşı karşıya olduğu görülmektedir. 2015’te \%22 olan işsizlik oranı 15-30 yaş grubu aktif nüfusu önemli bir şekilde etkilemektedir. Özellikle kırsal alanları etkilemekte olan bu durum besleyip gençlerin kırdan kente göç etmelerine yol açmaktadır. Çad istihdam ve işsizlikle ilgili olarak, bir yandan kolay bir şekilde iş bulamayan mezunlar ve diğer yandan ihtiyaç duydukları kalifiye işgücünü bulamadıklarını söyleyen şirketler kapsamında bir paradoks olduğu görülmektedir. Bununla birlikte talebi nitelikli olmayan işgücü arzı ile karşılanmaktadır. Dolayısıyla piyasa, mevcut nitelikler ve gereken nitelikler arasındaki uyumsuzluklar yüzünden işsizlikten mustariptir (UNFPA, 2015: 5).

\section{3. ÇAD'DA ENFLASYON ORANLARI}

Fiyat mekanizması; piyasa mekanizmasının en önemli unsuru olarak iyi bir şekilde çalışan bir rekabetçi piyasada arz ve talebin durumunu, malların kitlık derecesini göstermektedir. Fiyatlar genelde ekonominin işleyişini ve ekonomik faaliyetlerden ortaya çıkan sonuçları açıklamaktadır. Ekonomilerdeki mal ve hizmet fiyatlarındaki değişimi ise enflasyon oranı göstermektedir (Alacahan, 2011: 50).

Çad'da enflasyon analizi, N'djamena kentsel tüketici fiyat endeksine dayanmaktadır. Çad'da enflasyon oranlarının tarihsel gelişimi incelendiğinde -şekil 4'te gösterildiği gibi- petrol ihracatı projesinin hazırlıklarının başlamasıyla enflasyon oranları artmaya başlamış, 2001 yılında \%12 seviyesinde gerçekleşmişti. Bu artıştan sonra fiyatlar genel seviyesi, 2004 yılında art arda ikinci yıl için yıllık ortalama \%-5,4 oranında gerilemiştir. Fiyatlardaki bu gerileme, bir yandan gıda ürünlerinin piyasalara iyi bir şekilde arz edilmesi, diğer yandan da taleplerdeki düşüş ve petrol projesinde yer alan taşeronların faaliyetlerindeki yavaşlamaya bağlı olarak açıklanabilir (OECD, 2006: 533).

2004-2005 yıllarındaki kötü tarımsal sezon sonucunda gıda ürünleri arzında yetersizlik ortaya çıkmıştır. Bu olayın neticesinde fiyatlar genel seviyesi üzerinde baskı riski ortaya çıkmış, nitekim 2004 y1lında enflasyon oran $1 \% 3,3$ seviyesinde gerçekleşmiş, 2005 yılında $\% 8,1$ seviyesine kadar ulaşmıştır. 2007 yılında ise gida ürünlerindeki arz fazlasıyla (OECD, 2008: 626) genel fiyat seviyesi \%-7,4 oranında gerilemiştir.

İnsanların yaşam standartlarını önemli ölçüde etkileyen enflasyon, uluslararası düzeyde artan gıda fiyatlarının bir sonucu olarak 2012 yılında hızlanıp \% 7,7 seviyesine kadar artmışırır. 


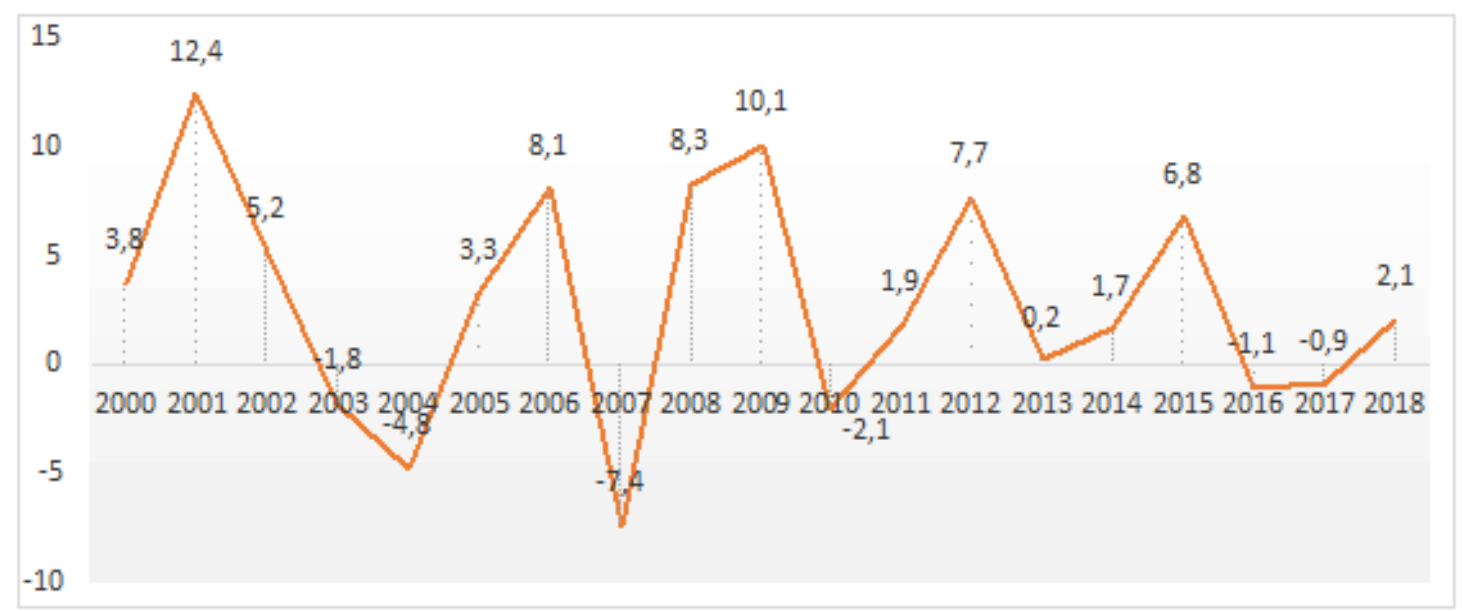

Şekil 4. Çad'da Enflasyon Oranları, (2000-2018 Ortalama Tüketici Fiyatları, Yıllık\% Değişim)

Kaynak: IMF Data Base (2020)

2014 yılında enflasyon oranı \%1,7 seviyesinde kalmışken 2015 y1lında \%6,8 seviyesine kadar artmıştır. Bu artış gıda ürünleri arzındaki düşüş ve onu takip eden gıda fiyatlarındaki artışa bağlıdır (Nations Unies, 2017: 10). 2016 yılında, mal ve hizmet pazarında tarımsal ürün tedarikindeki iyileşme sayesinde enflasyon oran $1 \%-1$ seviyesine kadar gerilemiştir.

Çad'ın bazı bölgelerinde düşük yağış nedeniyle tahıl üretiminde düşüş yaşanmış ve komşu ülkelerle (özellikle Kamerun, Nijerya ve Libya) yapılan ticarette kesintiler olmasıyla, piyasalarda arz zayıf olmuştur. Bütün bu olaylar 2015 yılında gida fiyatlarında yükselişe neden olmuştur. Bu eğilimden etkilenen ana kalemler; yiyecek ve alkolsüz içecekler, alkollü içecek ve tütün, sağlık, ulaşım, giyim ve ayakkab1, eğitim ve çeşitli ürün ve hizmetlerdir (Nations Unies, 2017:10).

Şekil 4'te gösterildiği gibi, 2018 yılında enflasyonist baskılar 2016 ve 2017 y1llarındaki gözlenen düşüş eğilimin ardından devam etmektedir. Fiyatlar genel seviyesindeki bu değişiklik, esasen iki nedene bağlanmaktadır. Bunlar; 2018 yılının başından bu yana gözlenen fiyatlardaki sürekli yükselişe bağlı olarak petrol faaliyetlerinin sürdürülmesini etkileri ve devletlerin petrol dışı gelirlerini artırmak amaciyla, CEMAC ${ }^{1}$ (Orta Afrika Ekonomik ve Parasal Topluluğu) ülkelerinde uygulamaya konulan yeni vergi sistemlerinin etkileridir (Banque de France, 2018: 3).

\section{CARİ İŞLEMLER DENGESI}

Son yıllarda uluslararası sermaye hareketlerinin çok büyük boyutlara ulaşması, ülkelerin herhangi bir finansman sorunu yaşamadan yüksek seviyede cari işlemler açığı vermelerine sebep olmuştur. Ancak yüksek düzeyde gerçekleşen cari işlemler açıkları aynı zamanda, ekonomilerin dış şoklara karşı kırılganlığını da artırabilmektedir. Bu nedenle cari işlemler açığı veren ülkeler oldukça önemli bir sorunla karşı karşıyadırlar (Tunalı, 2008: 163-164).

Genel olarak cari işlemler hesabı bir ekonomide, yurtiçi yerleşikler ile yurtdışı yerleşikler arasındaki mal ve hizmet hareketleri, faktör geliri ve giderleri yanında transferlerin izlendiği hesaptır.

\footnotetext{
${ }^{1}$ Orta Orta Afrika Ekonomik ve Parasal Topluluğu' (CEMAC) altı Orta Afrika ülkeleri (Kamerun, Çad, Orta Afrika Cumhuriyeti, Gabon, Ekvator Gine'si ve Kongo) bir araya gelip bir gümrük birliği kurmuşlar. CEMAC'1 kuran antlaşma 16 Mart N'djaména'da (Çad) imzalanmış ve Haziran 1999'da yürürlüğe girmiştir. Merkez yeri Bangui- Orta Afrika Cumhuriyeti.
} 
Cari işlemler hesabı açık verdiğinde ülke, yurt dışından kazandığı paradan daha fazlasını, yurt dışına göndermiş demektir. Bu bağlamda oluşan açık, dışarıdan borç alarak veya yurtiçi varlıkların satılması ile kapanabilir. Bu durumun tersi olduğunda, yani cari işlemler hesabı fazla verdiğinde yurtiçi yerleşikler tarafından yurt dışına sermaye transferi gerçekleşmiş demektir (Kadooğlu Aydın, 2017: 32).

Cari işlemler dengesi bir ekonominin dış dünya ile ilişkisi açısından son derece önemli bir konudur. Çünkü cari fazla veren ülkenin dış varlıkları artmakta ve cari işlemler açığı veren bir ülkenin ise dış yükümlülükleri artmaktadır. Dış varlık ya da yükümlülüklerde meydana gelen bu değişimler DYY (doğrudan yabancı yatırımlar) ve dış borçlanma ile karşılanmaktadır. Bir ülkenin cari işlemler hesabındaki değişiklikler ekonominin performansı ile ilgili önemli göstergelerden biri olarak değerlendirilmekte, bunun için iktisadi kararların ve beklentilerin oluşmasında önemli bir rol oynamaktadır (Kadooğlu Aydın, 2017:33 ve Erdoğan ve Bozkurt, 2009:137).

Çad'da cari işlemler açığı 2003 yılında (Şekil 5'te)-1,36 milyar dolardan 2004 yılında-0,76 milyon dolar seviyesine kadar gerilemiştir. Bu düşüş, ham petrol ihracatındaki önemli artıştan kaynaklanan 762,8 milyar CFA Franklık bir ticaret açığının ortaya çıkmasıyla ilişkilidir. Petrol projesinin inşası için yapılan yoğun ithalat nedeniyle cari işlemler dengesi açığı -şekil 5'te gösterildiği gibi- 2002 yılında GSYH'nin \%84,4'ü seviyesindeydi. Gerçekleştirilen ilk petrol ihracatından sonra bu açık azalmaya başlamış 2004 y1lında \%15 seviyesine inmiş sonraki yıllarda artan petrol ihracatı ile cari işlemler dengesi fazla vermeye başlamıştır. 2008 yılında cari fazla 0,37 milyon dolar seviyesinde gerçekleşmiştir. Bu rakam aynı zamanda GSYH'nin \%3,6'sına karşılık gelmektedir.

Cari işlemler açığı 2011 yılında artmaya başlayıp 2014 yılında 1,19 milyar Dolardan (GSYH'nin \%-8,9'u) 2015 yılında 1,49 milyar Dolara (GSYH'nin \%-13,6'sı) kadar tırmanmıştır. Bu açık, mal ve hizmet ihracatında -özellikle petrol, tarım ve hayvancılık sektörlerinde- ortaya çıkan \% 14,5 'lik düşüş ve ithalattaki \%1,6'lık artıştan kaynaklanmıştır. Ham petrol satışları, uluslararası düzeyde petrol fiyatlarındaki daralma ile paralel olarak gerilemiştir. Tarım ve hayvancılık ürünleri ihracatı ise komşu ülkelerin sınırlarındaki ortaya çıkan güvensizlikten etkilenmiştir. Zira, Boko Haram grubunun bölgedeki yarattığı güvensizlik sorunları, başta Kamerun, Nijer ve Nijerya olmak üzere komşu ülkelerle olan ticareti ciddi anlamda bozmuş (Nations Unies, 2017: 11-12) 2016 yllında GSYH'nin \%9,2'si düzeyinde gerçekleşmiştir.

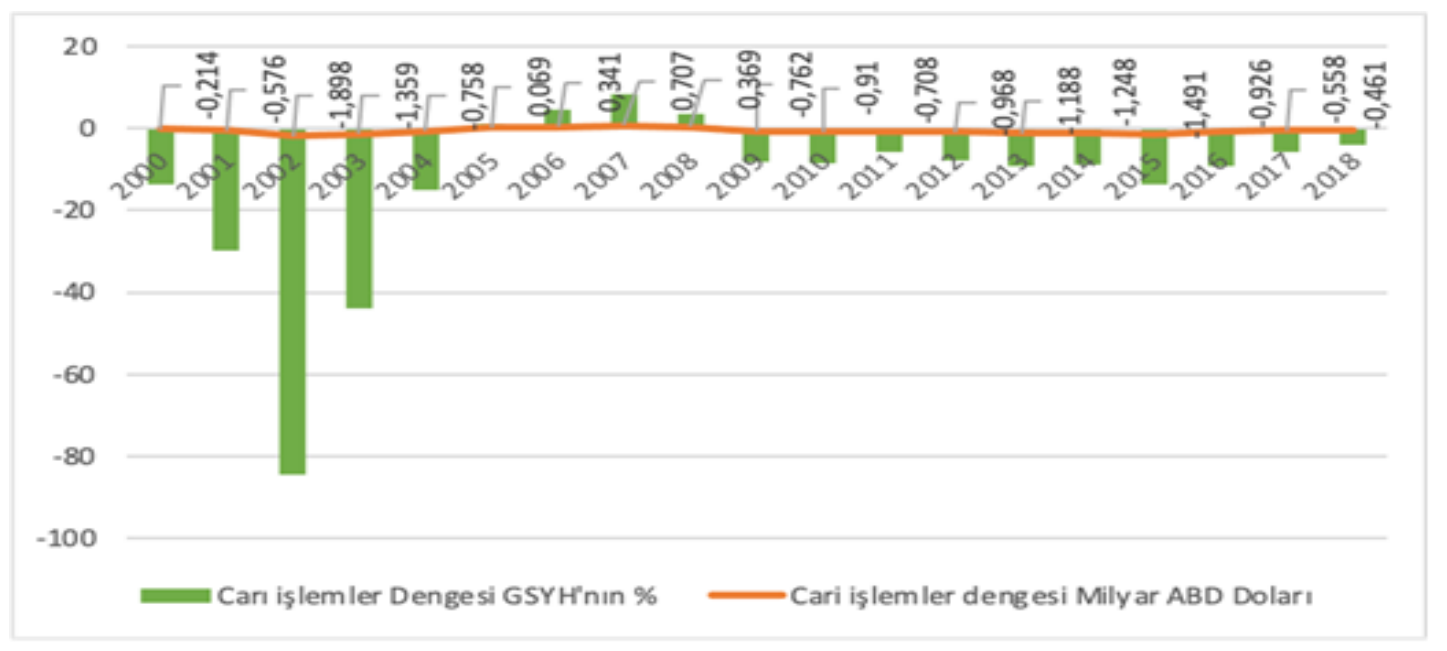

Şekil 5. Çad'ın Cari İşlemler Dengesi (2000-2018, Milyar ABD Doları) ve GSYH Değerleri (\%)

Kaynak: IMF Data Base (2020). 
Çad ekonomisi, petrol fiyatlarındaki dalgalanmalara karşı çok savunmasızdır. Petrolün toplam ihracattaki payı yavaş da olsa azaltılmakta ise de (2013'te \%82,7, 2014'te \%79,1 ve 2015'te \%77,4), petrol hâlâ ihracatta en önemli kalemdir. Bu durumun daimî niteliği, ekonominin yapısal dönüşümünün yetersizliğini vurgulamaktadır. Bunun yanında, petrol harici ihracatın hayvancılık, pamuk ve Arap zamk1 gibi birkaç sektörde yoğunlaştığı ve bu kalemlerin toplam ihracata katkılarının 2015 yılında sirayla \%6, \%3,5 ve \%5,4 olduğu tahmin edilmektedir (Nations Unies, 2017:12).

\section{CCAD'DA YABANCI SERMAYE}

1980'li yıllardan itibaren hız kazanan küreselleşme olgusu, yabancı sermaye hareketlerinin serbestleşmesinin bir neticesi olarak ulusal ekonomilerin küresel ekonomik yapıya eklemlenmesini sağlamıştır. DYY, sermaye birikimi azlığ 1 veya tasarruf eksikliği yaşanan az gelişmiş ve gelişmekte olan ülkeler için bu sorunların giderilmesinde etkili bir unsurdur (Mahamat, 2017: 92).

Az gelişmiş ülkelerin en önemli sıkıntılarından biri sermaye birikimlerinin yetersizliğidir. Yabancı sermaye, ev sahibi ülkenin hem sermaye birikimine hem de üretim kapasitesine dolaysız olarak katkıda bulunmaktadır. Yabancı sermaye sağlayacağı yeni üretim kapasitesiyle ülkenin reel üretiminin artmasına ve istihdamın genişlemesine olanak sağlamaktadır. Bu şekilde yabancı sermaye yatırımları, yaratacağı yeni iş firsatları ile ülkenin işsizlik sorununun çözümüne katkı sağlayabilir. Diğer yandan, yabancı sermaye ülkeye girerken, teknoloji ve işletmecilik bilgisi de getirmektedir. Dolaysıyla yabancı sermaye yatırımları, uluslararası teknoloji transferi yollarından birini oluşturmaktadır. Ev sahibi ülkeler yabancı işletmelerden, kendi ülkelerinde araştırma ve geliştirme faaliyetinde bulunmalarını ve yerli personeli modern teknoloji ve işletmecilik konularında eğitimlerini beklemektedirler (Seyidoğlu, 2015: 667-668).

Çad'da DYY'lerin yaklaşık \%80'i sanayi sektöründe yoğunlaşmaktadır. Ancak bu sektördeki yatırımların \%95'i petrol sektörüne yapılmakta, geri kalan \%20'lik pay ise diğer sektörler arasında dağılmaktadır. Fransa, pamuk üretim şirketi ile tarım alanındaki DYY’larda önemli bir paya sahip olup tekelci konumdadır. Sektördeki Fransız varlı̆̆ 1 şeker kamışı işleme ile (Vilgrain-şeker, Dagris-pamuk, Castel-bira şirketleri ile) sağlanmaktadır. Petrol alanındaki yatırımlar ise Exxon şirketi ile Amerikalı ve Malezyalı şirketlerin yatırımlarından oluşmaktadır. Fransız DYY'ları en çok hizmet sektöründe (\%50'sine sahip) faaliyet göstermektedir. Fransız DYY'ları petrol ürünleri dağılımında (Schlumberger ve Foraco); ulaştırma, transit geçiş, restoranlar ve oteller sektörlerinde ise Accor ve Mériden grupları temsil etmektedir. Finans sektörü; Societe Generale, Biat, Financial, Gras Savoye tarafindan temsil edilmektedir (Nguhouo İbrahim, 2008: 38). Çad'daki Fransız yatırımların büyüklüğü 2017'de \%0,6 düşüşle 109,4 milyon Euro'ya ulaşmıştır (Nembot, 2018: 1).

Çad'a yönelik DYY girişlerinde Çin'in payı oldukça büyüktür. Çin farklı alanlarda Çad'a imtiyazlı finansman sağlamaktadır. Özellikle Baoré Çimento projesi ve telefon ekipmanları alanında önemli yatırımlarda bulunmuştur (toplam 110 milyon Dolar). Çin, Çinli petrol şirketi (CNPC) yoluyla Bongor'daki petrol sahasını geliştirme çalışmalarına katılmaktadır. Djarmaya - N'djaména petrol hattının inşa projesine 160 milyon Dolarlık bir finansman sağlamıştır. Son beş yılda Çad'daki Çin'li taahhütlerin (krediler veya DYY şeklinde) 1,5 milyar Dolardan fazla olduğu tahmin edilmektedir. Hindistan ise, kredi şeklinde Çad'a 50 milyon Dolarlık bir finansman sağlamıştır. Bu kredi eğirme, traktör montajı, meyve suyu fabrikası, tel çekme, bisiklet montajı gibi küçük sanayi projelerinde kullanılmıştır (République Français, La direction générale du Trésor, 2017). 
2000 yılından itibaren ortaya çıkan petrol sektörüyle doğrudan yabancı yatırım projeleri teşvik edilmeye başlanmışıtır. 1960'lı yıllardan 1990'lara kadar, uzun süren siyasi istikrarsızlık ve çatışmalar, yatırımların artmasını engellemiştir. 1970 yılından 1999 yılına kadar Çad'da DYY seviyesi yıllık ortalama olarak 15 milyon Doları geçmemiştir ve hatta 1979, 1980, 1981, 1982 ve 1983 yıllarında Çad'daki DYY'ların hacmi sıfır seviyesindedir (Mahamat, 2017: 68).

Petrol ihracatı için Kamerun aracılığıyla bir boru hattının inşa çalışmasının başlamasıyla yabancı yatırımlar Çad'a akmaya başlamıştır. 2003 yılında petrol ihracatının başlaması ile petrol sektöründe faaliyet gösteren özel yatırımlar ortalama olarak yılda GSYH'nin \%8'ini oluşturmaktaydı. Yani söz konusu yatırımlar petrol ihracatına başlamadan önceki dönemlere göre yabancı doğrudan yatırımlar üç katından fazla artmıştır. Petrol sektörü 2000 ve 2013 yılları arasında Çad'a 10 milyar dolarlık bir gelir sağlamıştır (FMI, 2016: 40).

Petrolün ilk ihracatı gerçekleştirilmesinden bir yıl önce, yani 2002 yılında, şekil 6' da gösterildiği gibi Çad'a gelen 924,12 milyon Dolar değerindeki DYY GSYH'nin \%46,5'ini oluşturmuştur. 2003'te ise (petrolün ilk ihracat yıl1) 712,7 milyon Dolar seviyesindeydi.

2005- 2007 yılları arasında Çad'a DYY girişi olmamıştır. Bunun sebebi, 2005 yılında İdriss Deby Hükümeti karşıtı bir askeri ayaklanma hareketidir. 13 Nisan 2006'da N'djamena'da bir askeri darbe girişimi olmuş, ancak başarılı olmamıştır. Bu gelişmeler Çad'da bir güvensizlik ortamı yaratmış ve ülkeye DYY akımlarını engellemiş̧ir. Bu dönemde Çad'da DYY'nin GSYH'ye oranı 2005'te \%-1,49, 2006 ' da \%-3,75 ve 2007 'de \%-3,72 düzeyindedir.

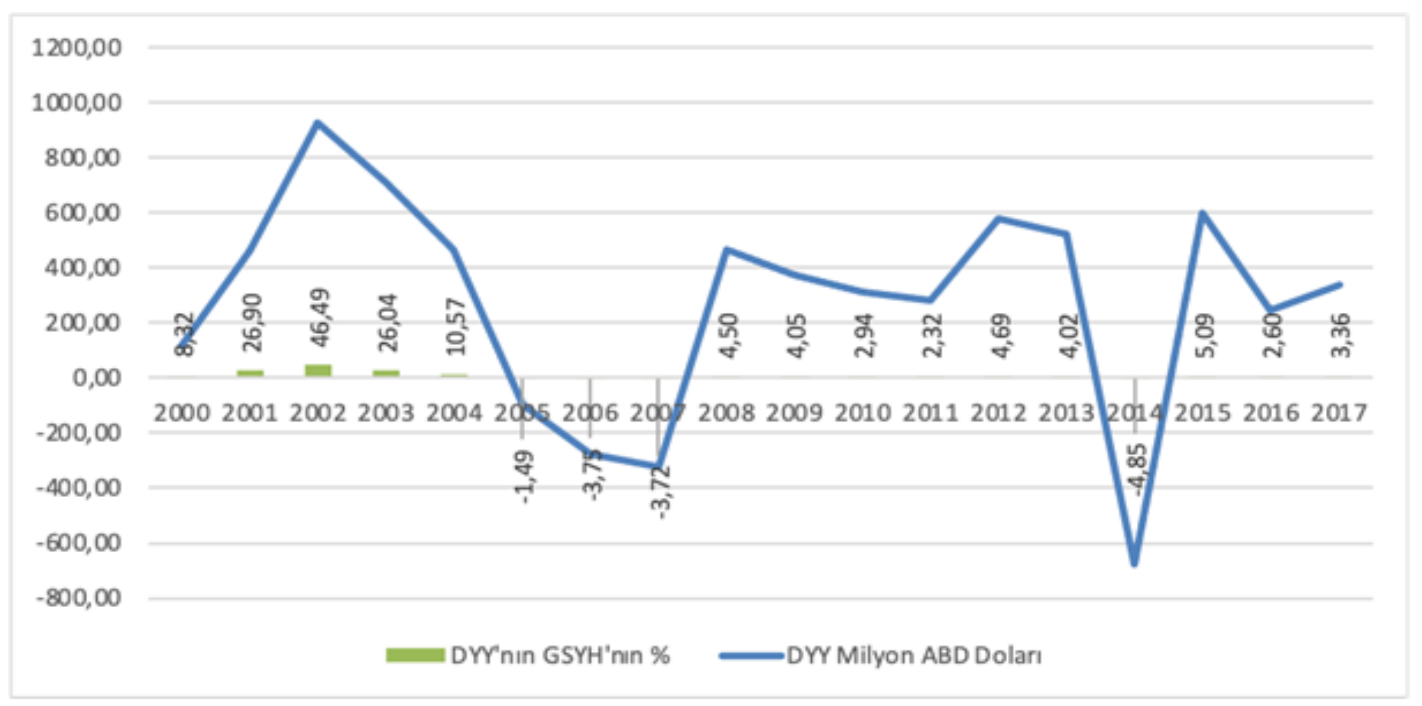

Şekil 6. Çad'a gelen DYY'ların Tarihsel Gelişsimi (2000-2017)

Kaynak: IMF Data Base (2020)

2006 yılındaki başarısız darbe girişiminden sonra 2008 yılının başına kadar Çad siyasi istikrarsızlık yaşamıştır. 2 Şubat 2008'de başkentte ikinci askeri darbe girişimi gerçekleştirilmiş ve bu girişim de başarılı olmamıştır. Bu gelişmelerle birlikte Çad'daki yatırım projelerinin çoğu petrol alanlarına yönelmiş ve hareketleri inişli-çıkışlı bir trende seyretmiştir. 2008 yılının sonunda Çad ve Çin'in imza attıkları Djarmaya Rafineri projesi ve Baoré Çimento inşa projesi ile Çin'den Çad'a 466,1 milyon Dolarlık DYY girmiştir (Adam, 2012). 
Son yıllarda Çad'ın en etkin yatırım alanı olan petrol fiyatlarındaki düşüş, 2014 yılında DYY hacmini sıfırın altına düşürmüş ve DYY çıkışları GSYH'nin \%4,85'ine ulaşmıştır. 2014'te Çad'dan 675 milyon Dolarlık DYY çıkışı olmuştur.

13 Haziran 2014 yılında Fas Gayrimenkul Komisyoncusu Addoha ile Çad hükümeti arasında bir antlaşma imzalamıştır. Anlaşma kapsamında; Başkentte (N'djamena'da) 15.000 sosyal konut ve bir Çimento fabrikası (30 milyon Euro değerinde bir proje) inşa edilmesi öngörülmüsştür (Journal du Tchad.com, 2014). 2015 yılında Fas Gayrimenkul Komisyoncusu Addoha'nın inşa edeceği Çimento projesi ve petrol alanındaki yeni keşif projeleri sayesinde Çad'a 600 milyon Dolarlık DYY girişi olmuştur.

\section{6. ÇAD'DA FINANS SEKTÖRÜ}

Finans sektörü, Afrika ülkelerinin ekonomik performanslarını belirlemekte önemli bir rol oynamaktadır (Ahmat Ali, 2016: 1). Sanayileşmiş ülkelerde, bankacılık sistemi önemli bir işlevi yerine getirmektedir. Zira sistem, yatırım amaçlı oluşturulan fonların yeniden dağıtılmasına yardımcı olup bir yandan üretim faaliyetlerini finanse etmeyi mümkün kılmaktadır. Ancak Afrika ülkelerinde, bankalar kendilerine düşen finansal arac1lık rolünü yerine getirmemektedirler (Nguyen, 2008:65). Gelişmekte olan ülkelerde, bu sorun finansal baskı bağlamında analiz edilmektedir. Hükümet düzenlemeleriyle bu ülkelerin finansal sistemlerinde kısıtlamalar uygulanıp sektörün gelişmesini veya genişlemesini engellemektedir. Genel olarak finansal baskı, finansal derinleşmeyi ve dolaylı bir şekilde ekonomik kalkınmayı da engellemektedir (Ahmat Ali, 2016:1).

Çad'ın petrol projesinin başlamasıyla, ülkede bankacılık sistemindeki oyuncuların büyüklüğünün ve sayısının arttığı görülmüştür. Nitekim bankacılık sektörü 2005-2011 yılları arasında üç kat artan banka sayısının yanı sıra günümüzde bankacılık sektörüne yönelik önemli teşvikler bulunmaktadır.

Çad'da bankacılık piyasası sekiz banka tarafından yönlendirilmektedir. Bunlara bazı banka dışı finansal kurumlar da eklenebilir. Üç banka (Ecobank, Orabank ve Société Générale) mevduatın pazar payının yarısından fazlasıyla sektöre hakimdir. Piyasaya yakın bir zamanda girmesine rağmen (2006), eski BIAT'ın (Çad'daki Uluslararası Afrika Bankası) varlıklarını satın alan Ecobank, 2012 yılının sonunda toplanan 550 milyar CFA Frank tutarındaki mevduatın \%26'sını elinde bulundurarak listenin başında yer almıştır. Diğer bankalar sırasıyla (2013 verilerine göre) Orabank Çad (mevduatın \%19'u), Societe Generale Çad (\%17) ve Ticaret Bankası Çad (\%16) şeklinde sıralanmaktadır. UBA (Afrika Birleşik Bankası), 2009 yılında faaliyete geçmesine rağmen, mevduatın \%6'sını elinde bulundurmaktadır (Gab-Leyba, 2015).

Bu gelişmeler ekseninde Çad'da mevduat hacmi, 2005 y1lında 129 milyar CFA Frank'ından yaklaşık \%382,5'lik bir oranla büyüyerek- 2013 yılında 623 milyar CFA Frank'in üzerine çıkmıştır. Ancak mevduatın \%84'ü vadesiz mevduat, kalan \%16'l1k oran ise vadeli mevduattır.

2014 yılında kümülatif banka bilançoları \%15,6 artarak 958,7 milyar CFA Frank’ına yükselmiştir. $\mathrm{Bu}$ artış, ağırlıklı olarak müşteri mevduatlarındaki artıştan kaynaklanmaktadır. Müşteri mevduatları $\% 29,3$ oranında büyürken devlet mevduatı $\% 22,1$ oranında gerilemiştir. Krediler, 2014'te \%15,4 büyüyüp 630,2 milyar CFA Frank seviyesine yükselmiştir. Bu artş̧, özel şirketlerde brüt taahhütlerdeki artıştan $(\% 19,1)$ kaynaklanmaktadır. Öte yandan devlete olan borçlar keskin bir şekilde $(\% 21,1)$ azalıp 47,7 milyar CFA Frank seviyesine kadar gerilemiştir. Toplamda kredi/mevduat oranı 2014 yılında $\% 85,5$ oranında büyümeye devam etmiştir. 2013 yılında bu oran $\% 84,7$ ve 2012 yılında $\% 80,1$ 
seviyesinde gerçekleşmiştir. Buna karşılık, CEMAC bölgesinde bu oran \%72,4 seviyesinde gerçekleşmiştir (Banque de France, 2014: 255).

Çad'ın bankacılık sektöründe oligopolleşme söz konusudur. Toplam aktiflerin yaklaşık üçte ikisi üç ticari bankanın elindedir. En büyük iki banka, yabancı bankaların iştirakleridir ve devlet, diğer dört bankada toplam sermayelerinin \%20-62 arasında bir öz kaynak payına sahiptir. Finansal sistemin derinliği ve finansal katılım, Çad'da çok düşük kalmaktadır. Bankacılık oranı (en az bir banka hesabi olan nüfusun yüzdesi), Sahra altı Afrika'da ortalama \%34,2 iken Çad'da 2016 y1lında bu oran \%12 seviyesinde kalmıştır. Aynı dönemde, brüt krediler GSYH'nin \%9,1'ini oluşturmaktadır. Bu oran CEMAC bölgesi $(\% 18,6)$ ve tüm Sahra Altı Afrika bölgesi $(\% 29)$ ortalamalarının altındadır. Ayrıca, Çad'da yüzün üzerinde mikro finans kurumu bulunmaktadır. IMF'nin tahminlerine göre 2015 yılı sonunda, mikro finans sektöründen 18 milyar CFA Frank'lık kredi stokundan iki yüz bin kişi yararlanmıştır (Banque de France, 2017: 327).

Çad'da, petrol fiyatlarındaki düşüş ile finansal istikrarın bozulma riski arasındaki bağlantı çok belirgindir. $\mathrm{Bu}$ ise, bankaların faaliyetlerini özel üretici sektörlerle değil kamu kuruluşlarıyla gerçekleşmesidir. Nitekim, 2016 yılında ticari banka kredilerinin sadece \%4'ü özel sektöre kullandırılmıştır. Öte yandan, son zamanlarda kamu harcamalarındaki yaşanan düşüşler ve iç borçların birikmesi, özel sektör müteahhitleri ve borçluları için finansal zorluklara neden olmuştur. Bu durum, portföy kalitesindeki bozulmayı büyük ölçüde açıklamaktadır (Banque de France 2017: 328).

IMF’nin belirttiği gibi, Çad bankacılık sektörünün bilanço yapısındaki son değişiklikler hem aktifler hem de pasifler bakımından sistemi daha savunmasız hale getirmiştir. 2016'da toplam mevduatın \%85'i vadesiz mevduatlardır ve bu oran CEMAC ülkeleri arasındaki en yüksek orandır. Kamu transferlerinin azaltılması sonucunda, birçok kamu kuruluşu (örneğin, üniversiteler ve hastaneler) mevduatlarını bankalardan geri çekmek ya da banka kredisi işlemlerine başvurmak zorunda kalmıştır. Ayrıca, Hazine bonolarının çıkarılması (ortalama üç yıl vadeli) likit bir ikincil piyasa olmaması durumunda, kısa vadeli mevduatlar ve banka varlıkları arasındaki asimetrik vade riskini artırmaktadır. Son olarak, devlet tahvillerinin (orta vadeli) iç borçları ödemesi için çıkarılması kamu kuruluşlarının etkisini artırarak özel sektörün dışlanmasına neden olacağı öngörülmektedir (Banque de France, 2017: 328).

\section{SONUÇ VE DEĞERLENDİRME}

Bu çalışmada, 2000-2018 yılları arasında Çad ekonomisinin makro ekonomik göstergeleri incelenmiştir. Ekonominin istikrarı, ülke içindeki iktisadi aktörler açısından önemli olduğu kadar, uluslararası aktörler ve kurumlar açısından da büyük bir öneme sahiptir. Politika yapıcıları, politikaları tasarlamak ve değerlendirmek için istatistiksel göstergeler belirleyicidir. Ülke yerleşikleri ve yabanc1 yatırımcılar, siyasi yönetim anlayışını ve performansını değerlendirmek için bu göstergeleri ölçüt olarak kullanırlar.

Çad ekonomisinin makro ekonomik göstergeleri incelendiğinde, ekonominin büyümesi için gerekli olan çeşitliliğin yetersiz olduğu ve ekonomik büyümenin petrol ihracat hacmi ve fiyatına yoğun şekilde bağımlı olduğu görülmektedir.

Genel olarak, Çad'da genç nüfus eğitim seviyelerine bakılmaksızın bir istihdam sorunu ile karş1 karşıyadır. Çad'da son dönemde işsizlik oranın \%22'ye tırmandığı ve işsizliğin 15-30 yaş grubu nüfusu önemli bir şekilde etkilediği görülmektedir. İşsizlik sorunu özellikle kırsal alanları etkilemekte ve bu durum gençlerin büyük şehirlere göç etmelerine yol açmaktadır. Dolayısıyla genç işsizliğin bir taraftan 
dinamik nüfusun istihdam edilmemesi nedeniyle eksik istihdama ve üretim kayılarına, diğer taraftan ise kır-kent ayrımında gelirin eşitsiz dağılmasına yol açtı̆̆ söylenebilir.

Çad'da DYY girişlerinin petrol ihracatı ve petrolle ilişkili sektörler kapsamında artı̆̆ı, son dönemde ise petrol fiyatlarındaki dalgalanmalar nedeniyle DYY çıkışlarının olduğu görülmüştür. DYY gelmemesinin nedenleri ekonomik ve siyasal istikrarsılıklardan kaynaklandığını söylemek mümkündür. Çad'a DYY çekmek için öncelikle ekonomik ve siyasi istikrarı sağlanmalı ve daha etkili teşvik paketlerini uygulanmalıdır.

Çad'ın petrol projesinin başlamasıyla, ülkede bankacılık sistemindeki oyuncuların büyüklüğünün ve sayısının arttığı görülmüştür. Bankacılık sektörü 2005-2011 yılları arasında üç kat büyümüş ve bankacılık sektöründe yeni girişimlere yönelik önemli teşvikler verilmiş̧ir. Buna karşılık, Çad'da bankacılık sektörü oldukça dar yapılanmış olup, toplam aktiflerinin yaklaşık üçte ikisi sadece üç ticari bankanın elindedir. En büyük iki banka, yabancı bankaların iştirakleridir ve devlet, diğer dört bankada toplam sermayelerinin \%20-62 arasında bir öz kaynak payına sahiptir. Dolayısıyla finansal sistemin derinliği ve finansal katılım, Çad'da çok düşük kalmaktadır. Bu tespitler çerçevesinde, kapsayıcı büyümeye ilişkin kalkınma stratejilerinde savunulduğu üzere, ekonominin çeşitlendirilmesinin teşvik edilmesi gerekmektedir. Bu çeşitlendirmenin temel unsurlarından biri, finansal aracılık rolünü oynaması gereken finansal sektörün gelişmesidir. Ne yazık ki Çad sektörün gelişimi ve genişlemesini engelleyen birçok unsurla karşı karşıyadır.

Çalışmadan elde edilen bulgular neticesinde, Çad ekonomisinin son dönemdeki makro ekonomik olarak istikrarı henüz yakalayamadığını söylemek mümkündür. Bu durumun nedenleri arasında, uluslararası ticarete konu olan sektörlerin sınırlığı ve buna bağlı olarak yatırım çekme kabiliyetindeki eksiklikler gösterilebilir. Ekonomik anlamda çeşitlendirme politikalarının uygulanması ve dış şoklara daha az maruz kalan sektörlere de yatırım yapılması ile bu durumun olumsuz etkiler azaltılabilir. Ayrıca, yapısal bir görünüm arz eden işsizlik ve özellikle genç işsizlik sorununun aktif işgücü politikaları ekseninde yeniden gözden geçirilmesinin gerekli olduğu görülmektedir. Son olarak, ekonomik istikrara paralel şekilde siyasal istikrarın sağlanması da ekonomi politikalarını etkinliğini artırabilecektir. 


\section{KAYNAKÇA}

Adoum, S. (2012, Mai). Les investissements pétroliers chinois au Tchad. À la recherche d'un "gagnant/gagnant » ? Actuelle de l'İnstitut Français des relation internationales (IFRI). Erişim Adresi https://www.ifri.org/fr/publications/enotes/investissements-petroliers-chinois-tchad-recherchedungagnantgagnant.

Ahmat, A. I. (2016). Impact de la libéralisation financière sur la croissance économique : Cas du Tchad (19602014) [Yüksek Lisans Tezi, Université Abderrahmane Mira De Bejaia].

Banque Africaine de Développement, Fonds Africain de développement. (2009, Octobre). Tchad, Document de Stratégie Pays 2010-2014, Département Régional Centre.

Banque de France (2015). Rapport annuel de la Zone franc 2014. Eurosystème.

Banque de France (2017). Rapport annuel de la Zone franc 2016. Eurosystème.

Banque de France (2018). Situation Economique-CEMAC, Conjoncture Economique et Financière des Etats Membres de La CEMAC et Perspectives Pour 2019. Erişim Adresi https://www.banquefrance.fr/sites/default/files/media/2018/09/28/situation_economique_cemac.pdf.

CNUCED- Conférence des Nations Unies sur le Commerce et le Développement. (2016). Atelier de formation sur l'implication du secteur privé dans les activités pétrolières et minières au Tchad, N'Djaména, Tchad, 68 décembre 2016, Situation du marché de l'emploi au Tchad.

Dilbaz A., N. (2011). Enflasyon, Döviz Kuru İlişkisi ve Yansıma: Türkiye. Uygulamall Sosyal Bilimler Dergisi, $1(1): 49-56$.

Erdoğan, S. \& Hilal, B. (2009). Türkiye'de Cari Açığın Belirleyicileri: Mgarch Modelleri ile Bir İnceleme. Maliye Finans Yazllarl, 23(84): 135-172.

Fonds Monétaire International. (2016). Rapport $d u$ FMI No 16/275. Erişim Adresi https://www.imf.org/french/pubs/scr/2016

Gab-Leyba, G. D. (2015). Les faits : Le secteur bancaire tchadien en chiffres. Erişim Adresi http://www.crosettd.org/2015/06/les-faits-le-secteur-bancaire-tchadien-en-chiffres/.

Kadooğlu Aydın, G. (2017). Ödemeler Dengesi ve Cari Açık: Türkiye'de 2014-2016 Yılları Arasında Cari Açık ve Petrol Fiyatları Etkileşimi. Fırat Üniversitesi, İIBF Uluslararası İktisadi ve İdari Bilimler Dergisi, 1(2): 27-66.

L'Organisation de Coopération et de Développement Economique -OECD. (2006). Perspectives économiques en Afrique-Tchad. Erişim Adresi https://www.oecd.org/fr/dev/36803227.pdf.

L’Organisation de Coopération et de Développement Economique -OECD. (2008). Perspectives économiques en Afrique-Tchad. Erişim Adresi https://www.oecd.org/fr/dev/emoa/40571838.pdf

Luidor N. (16.06.2014). Tchad : lère pierre de la construction d'une nouvelle cimenterie, Journal du Tchad.com. Erişim Adresi http://www.journaldutchad.com/article.php?aid=6239.

Mahamat, Y. A. (2017). Teşvikler ve Kısıtlamalar Bağlamında Çad'da Doğrudan Yabancı Yatırımlar (Yayın No. 10166629) [Yüksek Lisans Tezi, Marmara Üniversitesi].

Mızırak, Z. (2018). Makroekonomik Göstergelerinin Analizi. İçinde Mızırak Z. \& Karabulut T. (Eds), İstihdam Sorunu ve Politikaları Kapsamında Türkiye'de İstihdam Görünümü (ss.171-204). Çizgi Kitabevi Yayınları: Konya

Mügge, D. (2016). Studying macroeconomic indicators as powerful ideas. Journal of European Public Policy, (23)3. 410-427.

Nations Unies. (2017). Profil de pays 2016, Tchad. Commission économique pour l'Afrique. Erişim Adresi https://repository.uneca.org/handle/10855/23690

Nations Unies-Tchad. Plan Cadre des Nations Unies D'assistance au développement (Undaf)- Tchad 2017-2021. Erişim Adresi https://chad.un.org/sites/default/files/2020-02/Tchad_UNDAF\%2020172021_Version\%20Sign\%C3\%A9e.pdf 
Nembot, A. (2018). Les IDE français au Tchad en 2017. Ambassade de France Au Cameroun Service Economique Régional. Erişim Adresi www.tresor.economie.gouv.fr/Articles/2019/01/21/ les-investissements-directsfrançais-au-Tchad.

Ngouhouo I. (2008). Les Investissements Directs Étrangers En Afrique Centrale : Attractivité Et Effets Économiques, [PhD Thesis in Economics, Université du Sud Toulon-Var]. Erişim Adresi https://tel.archives-ouvertes.fr/tel-00274376

Nguyen, D. K. (2008). Libéralisation financière et marchés émergents. Série le monde en question collection l'esprit économique. L'Harmattan : France

République Française, La direction générale du Trésor. (2017). Les services économiques à l'étranger- Tchad. Erişim Adresi https://www.tresor.economie.gouv.fr/Pays/tchad.

Seyidoğlu H. (2015). Uluslararası İktisat: Teori Politika ve Uygulama. Güzem Yayınları: İstanbul

Tunalı, Ç. B. (2008). Türkiye’de Cari İşlemler Açıklarının Sürdürülebilirliği. Sosyal Bilimler Dergisi, 1(1): 163177.

UNFPA (2015). Rapport de mission d'appui à l'élaboration du $7^{e}$ CPD de la composante « Adolescents et Jeunes » du 3 Novembre au 14 Décembre 2015. 


\section{EXTENDED ABSTRACT}

In this study, the macroeconomic outlook of Chad's economy between 2000-2018 is examined. In this context, national income indicators of Chad's economy are discussed first. Later, the labor force participation rate and inflation rate in Chad are examined. Afterward, the course of the current account balance and foreign capital are discussed. Finally, the financial sector in Chad is examined and the result obtained is explained in the conclusion part.

Many variables, such as growth rate, inflation, unemployment, and foreign trade deficit may be used as measures of an economy's stability. Needless to say, the stability of an economy is important not only for domestic economic actors but also for international actors and institutions. Policymakers use macroeconomic indicators to evaluate their economies' health. Citizens use these indicators as measures to evaluate politicians' performance.

Chad is, first and foremost, an agricultural nation. Its economy is heavily reliant on agriculture. More than $75 \%$ of the workforce is employed in this sector, which occupies 39 million hectares of arable land (but only 2.2 million hectares in use). The number and quality of livestock breeding offer Chad many potentials.

The start of the oil project in 2003 has brought new dynamics to Chad's economy and increased the annual growth rate of the country's gross domestic product (GDP) in recent years. The intensive export efforts in the oil sector in 2004 lead the Country's growth rate to reach a record level of 33,36 percent. However, with the decline in oil prices in recent years, Chad's GDP grew by (1.8\%) in 2015. The country faced a shrinkage of $7 \%$ in 2016 which was the lowest growth rate since 2000 . The result of this study shows that the variety of sectors that provide support for the economy is less and that the oil export volume and prices are more effective in the growth of the Chad's economy. Due to this fact, the real growth rate of the economy has been quite low in the years when oil prices were low.

When the historical development of Chad's economy is examined, it is seen that the economic performance of Chad was not bright since the year of independence, that is, from 1960 to 1990. Economic growth remained low as a result of the emergence of civil wars and the onset of political instability following independence. Between 1990-2000, Chad rebuilt its state and implemented new structural adjustment policies. With the structural adjustment policies, privatization movements, and liberalization of international trade in this period, the economic performance of Chad started to improve and the annual growth figures of GDP and GDP per capita figures started to increase. Chad's economy is highly vulnerable to fluctuations in oil prices. Although the oil's share in total exports is reduced slightly (82.7 percent in 2013, 79.1 percent in 2014, and 77.4 percent in 2015), it still remains the most important item in international trade. The permanent character of this superiority emphasizes the inadequacy of the structural transformation of the economy. Besides, exports excluding oil are concentrated in few sectors such as livestock, cotton, and gum Arabic, and their contribution to total exports is estimated to be $6 \%$, $3.5 \%$, and $5.4 \%$ in 2015 , respectively.

On the other hand, regardless of the education level of youth in Chad, they are faced with a serious unemployment problem. This unemployment affects rural areas, which feeds the flow of rural migration and leads young people to migrate to big cities.

The volume of FDI inflows to Chad has increased with the launch of the oil industry and oil exports that emerged in Doba in the southern region of Chad since 2000. In 2002, one year before the first export of oil, FDI inflows amounted to total of 924 million Dollars, which constituted 46.49\% of the GDP. In 2003, FDI inflows to Chad reached 713 million Dollars. The recent price decline in oil sector, which is the most effective investment area of Chad, reduced the volume of FDI and the FDI outflows constituted 4.85\% of GDP in 2014.

The depth of the financial system and financial participation remains very low in Chad. With the start of the oil project of Chad, it has been observed that both the number of actors and the volume of activities in the banking system increased. Today there is a significant incentive for establishing new banks in the banking sector. The diversification of the economy needs to be encouraged, as inclusive growth is encouraged in development strategies. One of the key elements of this diversification is the development of the financial sector, which must play the role of financial intermediation. 
Consequently, when we examine the macroeconomic indicators, it can be seen what extent Chad needs to diversify its economy. Recent declines in oil prices had obvious negative macroeconomic effects on the economy. As a result of the findings obtained from the study, it can be said that Chad's economy has not yet achieved stability in macroeconomic terms. Among the reasons for this situation, the limitations of the sectors that are subject to international trade and accordingly the deficiencies in the ability to attract investments can be shown. The negative effects of this situation can be reduced by implementing economic diversification policies and investing in sectors that are less exposed to external shocks. Besides, it is seen that the problem of unemployment and especially youth unemployment, which has a structural appearance, needs to be reviewed within the axis of active labor policies. Finally, ensuring political stability in line with economic stability can also increase the effectiveness of economic policies. 